\title{
VARIAÇÃO LEXICAL DO PORTUGUÊS: UM ESTUDO COMPARATIVO ENTRE O ATLAS LINGUÍSTICO-ETNOGRÁFICO DE PORTUGAL E DA GALIZA E ATLAS REGIONAIS BRASILEIROS
}

\author{
João Irineu de França Neto ${ }^{1}$
}

\begin{abstract}
Resumo
O presente artigo abordou as variações linguísticas no nível do léxico da língua portuguesa, estabelecendo comparações entre variedades do português europeu e do português brasileiro, tendo como base empírica os dados dos atlas linguísticos. Para tanto, foram selecionados o Atlas Linguístico-Etnográfico de Portugal e da Galiza (ALEPG), Atlas Linguístico da Paraíba (Alpa), Atlas Linguístico-Etnográfico da Região Sul do Brasil (ALERS). O problema de pesquisa foi o seguinte: existem convergências entre as variantes lexicais levantadas no Atlas Linguístico-Etnográfico de Portugal e da Galiza, no Atlas Linguístico da Paraíba e no Atlas Linguístico-Etnográfico da Região Sul do Brasil? Se existem, tais variantes permitem a constatação de áreas dialetais de encontro entre o português europeu e o português brasileiro? Nesta perspectiva, o principal objetivo da investigação foi o seguinte: estabelecer comparações diatópicas entre as variantes lexicais dos conceitos comuns ao atlas delimitados. A metodologia da pesquisa foi de caráter quantitativo, utilizando-se o Excel para sistematização e análise dos dados, além de se realizar uma discussão qualitativa dos itens lexicais. Utilizamos como referencial teórico autores da dialetologia e Sociolinguística, como Cardoso (2010), Álvarez Pérez (2012), Labov (2008), Tarallo (2002), dentre outros. Os resultados da pesquisa pretendem contribuir na elaboração de materiais didáticos para o ensino de língua materna na Educação Básica, fundamentados cientificamente nos dados empíricos das variedades lexicais que são faladas na região onde os educandos se situam socioculturalmente, levando-se em consideração as variedades locais do português.
\end{abstract}

Palavras-chave: Dialetologia. Variação. Português. Léxico.

\begin{abstract}
The present article dealt with the linguistic variations in the level of the lexicon of the Portuguese Language, establishing comparisons between European Portuguese and Brazilian Portuguese varieties, based on empirical data from the linguistic atlases. Therefore, the Linguistic-Ethnographic Atlas of Portugal and Galicia (ALEPG), Linguistic Atlas of Paraíba (ALPA), Linguistic-Ethnographic Atlas of Southern Region of Brazil (ALERS) were selected. The research problem was as follows: Are there any convergences between the lexical variants raised in the Linguistic-Ethnographic Atlas of Portugal and Galicia, in the Linguistic Atlas of Paraíba and in the LinguisticEthnographic Atlas of Southern Brazil? If they do exist, do these variants allow the

\footnotetext{
${ }^{1}$ Possui graduação em Licenciatura Plena em Letras pela Universidade Estadual da Paraíba (2005), especialização em Psicopedagogia, mestrado em Letras pela Universidade Federal da Paraíba (2008) e doutorado em Linguística pela Universidade Federal da Paraíba (2013). Atualmente é professor de linguística da Universidade Estadual da Paraíba - Campus III.
} 
verification of dialectal areas of encounter between European Portuguese and Brazilian Portuguese? In this perspective, the main objective of the research was: to establish diatopic comparisons between the lexical variants of the concepts common to the delimited atlases. The methodology of the research was quantitative, using Excel for systematization and data analysis, in addition to a qualitative discussion of lexical items. We use as theoretical references authors of dialecology and sociolinguistics, such as Cardoso (2010), Álvarez Pérez (2012), Labov (2008), Tarallo (2002), among others. The results of the research are intended to contribute to the elaboration of didactic materials for the teaching of mother tongue in Basic Education, scientifically based on the empirical data of the lexical varieties that are spoken in the region where the students are socio-culturally, taking into account the local varieties of the Portuguese.

Key-words: Dialectology. Variation. Portuguese. Lexicon.

\section{Introdução}

A Dialetologia, desde sua criação no final do século XIX, tem avançado na descrição da variação das línguas, nos seus diversos níveis - fonético-fonológico, morfossintático, lexical e semântico, por meio das pesquisas empíricas, nas quais ocorre o levantamento de um corpus de língua falada, possibilitando a categorização de fenômenos linguísticos, com base na concepção da heterogeneidade da língua. Desse modo, a concepção de que tudo na língua varia tem sido a grande contribuição teórica dessa vertente epistemológica da Linguística.

Nossa pesquisa abordou as variações linguísticas no nível do léxico da língua portuguesa, estabelecendo comparações entre variedades do português europeu e do português brasileiro, tendo como base empírica os dados dos atlas linguísticos. Para tanto, foram selecionados o Atlas Linguístico-Etnográfico de Portugal e da Galiza (ALEPG), Atlas Linguístico da Paraíba (Alpa), Atlas Linguístico-Etnográfico da Região Sul do Brasil (ALERS).

Levando em consideração que a comparação entre o ALEPG e Atlas Regionais Brasileiros não havia sido empreendida, nosso estudo constituiu-se como uma investigação inovadora do ponto de vista da descrição teórica da variação linguística em nível lexical. Neste sentido, relatamos no presente artigo uma análise de dados coletados no Estágio de Pós-doutorado em Dialetologia, realizado no Centro de Linguística da Universidade de Lisboa - CLUL - entre 2015 e 2016. 
O problema de pesquisa que norteou nossa investigação constituiu-se dos seguintes questionamentos: existem convergências entre as variantes lexicais levantadas no Atlas Linguístico-Etnográfico de Portugal e da Galiza, no Atlas Linguístico da Paraíba e no Atlas Linguístico-Etnográfico da Região Sul do Brasil? Se existem, tais variantes permitem a constatação de áreas dialetais de encontro entre o português europeu e o português brasileiro?

Nesta perspectiva, os objetivos da investigação foram os seguintes: Geral Estabelecer comparações diatópicas entre as variantes lexicais dos conceitos comuns ao Atlas Linguístico-Etnográfico de Portugal e da Galiza, ao Atlas Linguístico da Paraíba e ao Atlas Linguístico-Etnográfico da Região Sul do Brasil; Específicos: analisar as ocorrências de variantes lexicais com base nas respostas obtidas nos pontos de inquérito dos referidos atlas; identificar semelhanças geolinguísticas que aproximem as áreas dialetais portuguesas às áreas dialetais brasileiras; constatar indícios de variação estável e ou mudanças linguísticas no léxico do português nas diferentes áreas dialetais.

As Hipóteses da investigação são as seguintes: há uma elevada convergência entre as variantes lexicais dos conceitos dos Atlas Linguísticos analisados; há isoglossas convergentes entre regiões do território português e do território brasileiro.

Os resultados desta pesquisa pretendem contribuir, a posteriori, na elaboração de materiais didáticos para o ensino de língua materna na Educação Básica, fundamentados cientificamente nos dados empíricos das variedades lexicais que são faladas na região onde os educandos se situam socioculturalmente, levando-se em consideração as variedades locais do português bem como as de outras regiões geográficas.

\section{Dialetologia, Sociolinguística e Variação Lexical}

Os estudos dialetológicos tradicionalmente abordam a variação linguística, nos diversos níveis de realização da língua - fonético-fonológico, morfossintático, lexical e semântico, sob a perspectiva diatópica, isto é, a variação em áreas geográficas específicas. Por isso, a variação diatópica é chamada de geolinguística ou dialetal. "A fala em diferentes regiões possui características próprias. A Dialetologia é a disciplina que as procura descobrir e descrever, tentando identificar áreas mais ou menos coesas, assim como determinar os fatores que levaram à sua formação" (BARROS FERREIRA et al, 1996, p. 480). 
A Dialetologia se constituiu como um campo científico dos estudos linguísticos "que tem por tarefa identificar, descrever e situar os diferentes usos em que uma língua se diversifica, conforme a sua distribuição espacial, sociocultural e cronológica" (CARDOSO, 2010, p. 15). Tradicionalmente, este ramo linguístico, desde sua criação na primeira metade do século XIX, tem-se voltado para a criação dos chamados atlas linguísticos, os quais são constituídos de cartas geográficas acerca dos fenômenos das línguas em determinadas regiões de um estado, país ou continente.

Embora considere fatores sociais como escolaridade, idade, sexo dos falantes da língua, a Dialetologia, segundo a autora supracitada, tem como base a descrição da localização espacial dos fenômenos linguísticos, "configurando-se, dessa forma, como eminentemente diatópica" (CARDOSO, Op. cit., p. 26). Desse modo, a categoria de variação abordada pela Dialetologia é a variação diatópica, variação conforme a localidade ou região geográfica em que a língua se situa.

A Sociolinguística, ainda que estabeleça a intercomparação entre dados diferenciados do ponto de vista espacial, centra-se na correlação entre os fatos linguísticos e os fatores sociais, priorizando, dessa forma, as relações sociolinguísticas (CARDOSO, Op. cit., p. 26).

Neste sentido, conforme a descrição acima e toda a literatura científica da área, a Sociolinguística enfoca a temática da variação da língua sob uma perspectiva diastrática, enquanto que a Dialetologia descreve a variação diatópica. Entretanto, a tendência mais atual dos estudos no campo da Dialetologia é de uni-la à Sociolinguística, no que se convenciona chamar de pesquisas geossociolinguísticas.

Estas pesquisas estão no campo da Dialetologia Pluridimensional, que visa conciliar aspectos diatópicos e diastráticos, uniformizando o número de informantes, conforme critérios sociolinguísticos de sexo, faixa etária e escolaridade. Os Atlas Linguísticos que selecionamos para nossa investigação foram construídos com base na Dialetologia Monodimensional, a qual tem como foco o aspecto diatópico. Dos três atlas, o Atlas Linguístico da Região Sul do Brasil - ALERS - é o único que aborda também aspectos sociolinguísticos, além do caráter dialetológico. Contudo, ainda não chega a se constituir como um atlas da Dialetologia Pluridimensional.

O conceito de variação linguística repousa no fato de uma língua possuir “diversas maneiras alternativas de dizer 'a mesma' coisa” (LABOV, 2008, p. 21). Seguindo esta esteira, Tarallo (2002, p. 9) conceitua as variantes linguísticas de uma 
comunidade de fala como "diversas maneiras de se dizer a mesma coisa em um mesmo contexto, e com o mesmo valor de verdade. A um conjunto de variantes dá-se o nome de "variável linguística"”. Estuda-se, desse modo, a variação nos contextos do vernáculo falado, que se trata do "veículo linguístico de comunicação usado em situações naturais de interação social"' (TARALLO, Op. cit., p. 19).

A língua, na sua modalidade oral, varia em todos os níveis: fonético-fonológico, morfossintático, lexical e semântico. Nossa pesquisa realizou um levantamento das variações linguísticas no nível do léxico. Sobre tal nível linguístico, Villalva e Silvestre (2014, p. 23) estabelecem a seguinte definição:

O léxico de uma língua é, pois, uma entidade abstrata que se obtém por acumulação: às palavras em uso por cada falante, no seio de uma dada comunidade de falantes, juntam-se as palavras em uso por outras comunidades linguísticas falantes da mesma língua; às palavras em uso na contemporaneidade, somam-se as que estiveram em uso em sincronias passadas, de que temos notícia pela documentação escrita e que, por vezes, ressurgem; aos dados da escrita, unem-se os dados da oralidade, quando é possível apreendê-la, dada a muito maior fluidez da oralidade face à escrita.

Como observa-se acima, a formação do léxico envolve muitas forças, tanto na modalidade oral quanto escrita da língua. Interessou-nos na presente pesquisa documentar as unidades lexicais em seu processo de variação na oralidade, que foram acumuladas por diversas gerações e formam um conjunto lexical nas comunidades de falantes e são usadas por estes para fins de designação do mundo e dos contextos socioculturais em que estão inseridos.

Enquanto parte da gramática, o léxico pode ser visto como o lugar onde reside toda a informação que não é derivável, todas as propriedades idiossincráticas das línguas. É nesse papel que o léxico se distingue da sintaxe, da semântica e da fonologia, módulos que se encarregam da mecânica e da interpretação de enunciados frásicos, formados a partir da matéria-prima lexical, mas também se distingue da morfologia, a quem cabe a estruturação das palavras, igualmente formadas a partir de matéria-prima lexical (VILLALVA \& SILVESTRE, Op. cit., p. 28).

Desse modo, as variantes lexicais levantadas serão entendidas como variantes pelo fato de poderem substituir outras ou serem substituídas por outras na designação de um dado referente, sem que se altere a significação do referente, numa perspectiva de 
coexistência de variantes lexicais num momento sincrônico da língua, isto é, na contemporaneidade dos usos da língua. Corroboramos com o conceito de variação lexical estabelecido por Barros Ferreira et al (1996, p. 480), que consiste no "uso de palavras diferentes por diferentes comunidades para designar os mesmos conceitos", itens lexicais diferentes para se referirem a mesma significação.

\section{Metodologia}

A sistematização dos dados do corpus da pesquisa embasou-se no método comparativo, tendo como material de análise os dados lexicais do Atlas LinguísticoEtnográfico de Portugal e da Galiza (ALEPG), os quais encontram-se em uma base de dados digital, organizados cartograficamente de acordo com as regiões do território português onde foram documentadas; bem como as cartas léxicas do Atlas Linguístico da Paraíba (Alpa) e Atlas Linguístico-Etnográfico da Região Sul do Brasil (ALERS).

Nesta perspectiva, os procedimentos metodológicos da investigação foram a seleção e o levantamento dos conceitos convergentes nos dados do ALEPG, do Alpa e do ALERS, de acordo com cada campo semântico; bem como a organização de tabelas comparativas entre as variantes lexicais de cada conceito. A análise dos dados é de caráter quantitativo, mediante a utilização do Excel e a Base de Dados do ALEPG. O primeiro software foi utilizado na sistematização dos dados dos três atlas investigados, na perspectiva da produção de dados quantitativos, bem como representações desses dados na forma de gráficos. Assim, para cada conceito dos atlas, foram levantadas as variantes lexicais que os expressam em cada ponto de inquérito, sendo quantificadas nas planilhas do Excel. A referida Base de Dados foi utilizada para consulta e sistematização do corpus analisado, além da produção de mapas linguísticos.

As localidades do Atlas Linguístico da Paraíba (Alpa) são 25 municípios do referido estado: João Pessoa, Mamanguape, Belém, Guarabira, Itabaiana, Esperança, Campina Grande, Umbuzeiro, Barra de Santa Rosa, Picuí, Soledade, Cabaceiras, Taperoá, Serra Branca, Congo, Monteiro, Patos, Catingueira, Catolé do Rocha, Pombal, Princesa Isabel, Sousa, Itaporanga, Cajazeiras e Conceição (Cf. ARAGÃO, 1985, p. 17).

Os informantes foram escolhidos com base nos seguintes critérios: 
pessoa nascida na localidade ou no município; pertencente à faixa etária entre 30 e 75 anos; nível de instrução variando entre analfabeto e primário completo; não ter saído da localidade por mais de um ano; filhos de pais nascidos na região; possuir boas condições de saúde e de fonação; homens e mulheres; ter profissões variadas, por ser o questionário geral; trabalhar naquela produção específica, no caso do questionário específico (ARAGÃO, 1985, p. 17).

As variantes lexicais dos conceitos, registradas no (Alpa), sobre as quais tecemos nossas análises comparativas, são aquelas referentes ao questionário geral, que é constituído de 289 questões. Este questionário encontra-se organizado em torno dos seguintes campos semânticos: a terra, o homem, a família, habitação e utensílios domésticos, aves e animais, plantação, atividades sociais (Cf. ARAGÃO, 1985, p. 18).

A rede de pontos de inquérito do Atlas Linguístico-Etnográfico da Região Sul do Brasil - ALERS está dividida da seguinte forma: 100 pontos no Paraná, 80 pontos em Santa Catarina e 95 pontos no Rio Grande do Sul, totalizando 275 pontos em áreas rurais dos três estados, com finalidade de documentação da variação diatópica. Além dessas localidades, há 19 pontos de inquérito em centros urbanos, que tiveram uma finalidade sociolinguística mais específica, isto é, no concernente à variação diastrática. Desse modo, a rede de pontos do ALERS é constituída ao todo de 294 localidades (Cf. ALERS, 2011, p. 26; 59).

No tocante ao Questionário Semântico-Lexical (QSL), o ALERS possui 644 itens (lemas), que tem a finalidade do estabelecimento dos conceitos. Foram publicados 374 mapas, a partir de uma seleção dos lemas do QSL (Cf. ALERS, 2011, p. 26; 30).

Foi realizado um levantamento dos conceitos presentes no Atlas LinguísticoEtnográfico de Portugal e da Galiza (ALEPG), que coincidem com aqueles presentes no Atlas Linguístico da Paraíba (Alpa). Em seguida, foi realizado o levantamento dos conceitos do ALERS, tendo por base o primeiro procedimento comparativo, isto é, o confronto entre os conceitos do ALEPG e do Alpa.

\section{Resultados e discussões}

Neste tópico, apresentamos algumas análises parciais dos resultados que obtivemos mediante as sistematizações dos dados do ALEPG, Alpa e ALERS. Ressaltamos que a quantidade de dados levantados servirá de base para diversos artigos 
de descrição dialetológica da língua portuguesa, quer numa perspectiva sincrônica quer numa perspectiva diacrônica, lançando-se mão de dados de outras épocas para este segundo percurso de pesquisa. Desse modo, as discussões que seguem são análises comparativas das variantes lexicais de apenas alguns dos conceitos identificados nos três atlas que foram alvo de nossas investigações.

\subsection{Variantes lexicais para o conceito de arco-íris}

Para a designação do conteúdo conceptual de arco-íris, foram registradas, no Atlas Linguístico da Paraíba (Alpa), 10 variantes lexicais, totalizando 60 ocorrências nos 25 pontos de inquérito ao longo do Estado da Paraíba. Dessas variantes lexicais, as que apresentaram maior número de ocorrências são as que estão representadas no gráfico abaixo:

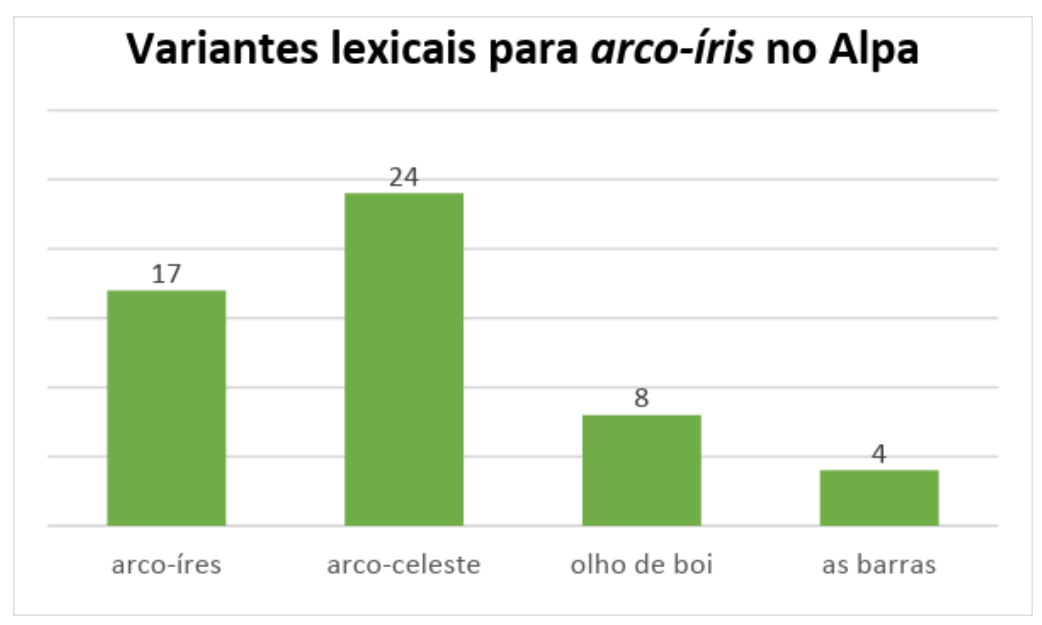

Fonte: Produzido pelo autor, com base nos mapas e quadros do Alpa.

A variante lexical "arco celeste" foi documentada em 24 pontos de inquérito do Estado da Paraíba, o que corresponde a quase totalidade dos pontos do Estado, não aparecendo apenas no ponto 5 - Itabaiana. Tal variante, neste sentido, revelou-se a mais produtiva nas respostas para expressar o conceito de arco-íris, correspondendo a $40 \%$ do total de ocorrências, seguida da variante "arco-íris" que é de 28,3\%, aparecendo em 17 pontos de inquérito. Tal resultado desconstrói uma ideia pré-estabelecida no pesquisador de que a variante lexical que mais irá aparecer nas respostas dos 
informantes é o item lexical que designa o conceito, isto é, que foi postulado como o lema daquele conteúdo semântico.

A variante "olho de boi" não aparece documentada no ponto 4 dos dados do Alpa - Guarabira. Entretanto, registramos tal variante linguística em uma entrevista dialetológica com um informante do sexo masculino, 57 anos de idade, analfabeto, residente em Tananduba, zona rural do referido município. O que isto pode revelar? Um acréscimo no repertório lexical? Seria um indício de um processo de mudança linguística no nível do léxico? São questões que ficam em aberto, posto que não possuímos dados suficientes para afirmar categoricamente uma conclusão sobre tal fato. Desse modo, esta incerteza quanto a um processo de mudança linguística e o registro da variante na região constituem-se como um degrau para uma investigação posterior, com um caráter mais sociolinguístico ou etnolinguístico.

Sobre a variante "as barras", verifica-se que esta não foi documentada na fala de pessoas do litoral paraibano. As quatro ocorrências da lexia situam-se nos pontos 6 (Esperança), 14 (Serra Branca), 17 (Patos) e 21 (Princesa Isabel), o que nos leva identificá-la diatopicamente como uma variante linguística da região do Brejo, Cariri e Sertão paraibano.

As demais variantes lexicais documentadas no tocante ao referido conceito foram: "as torres" (2 ocorrências) e "sub-dourada", "os vieiras", “arco", “cu de boi” e "os véus", cujas documentações foram em apenas um ponto de inquérito.

A lexia "arco", pelo que se observa, consiste numa redução morfológica das lexias compostas "arco-íris" ou "arco-celeste", cuja permanência do elemento substantivo, ao invés do adjetivo na construção do lexema simples "arco", evidencia a função lexical primordial que é nomear os referentes.

As variantes "cu de boi" e "os vieiras" consistem em lexias complexas, tendo sido a primeira documentada no ponto 21 (Princesa Isabel) e a segunda no ponto 24 (Cajazeiras), o que demonstra serem especificidades diatópicas dessas localidades. Um estudo sobre as motivações semânticas dessas designações lexicais demandaria uma imersão nos contextos extra-linguísticos dos usos empíricos nas localidades onde foram registradas. Caso não haja registros dessas motivações nas respostas ao questionário aplicado na época da pesquisa de campo, fica para os investigadores da Linguística uma lacuna de conhecimento léxico-semântico, que demanda o seu preenchimento com uma pesquisa de caráter linguístico-etnográfico, tendo como foco apenas essas variantes 
lexicais, no concernente aos sentidos que os usuários da língua da região do sertão atribuem a essas formas linguísticas.

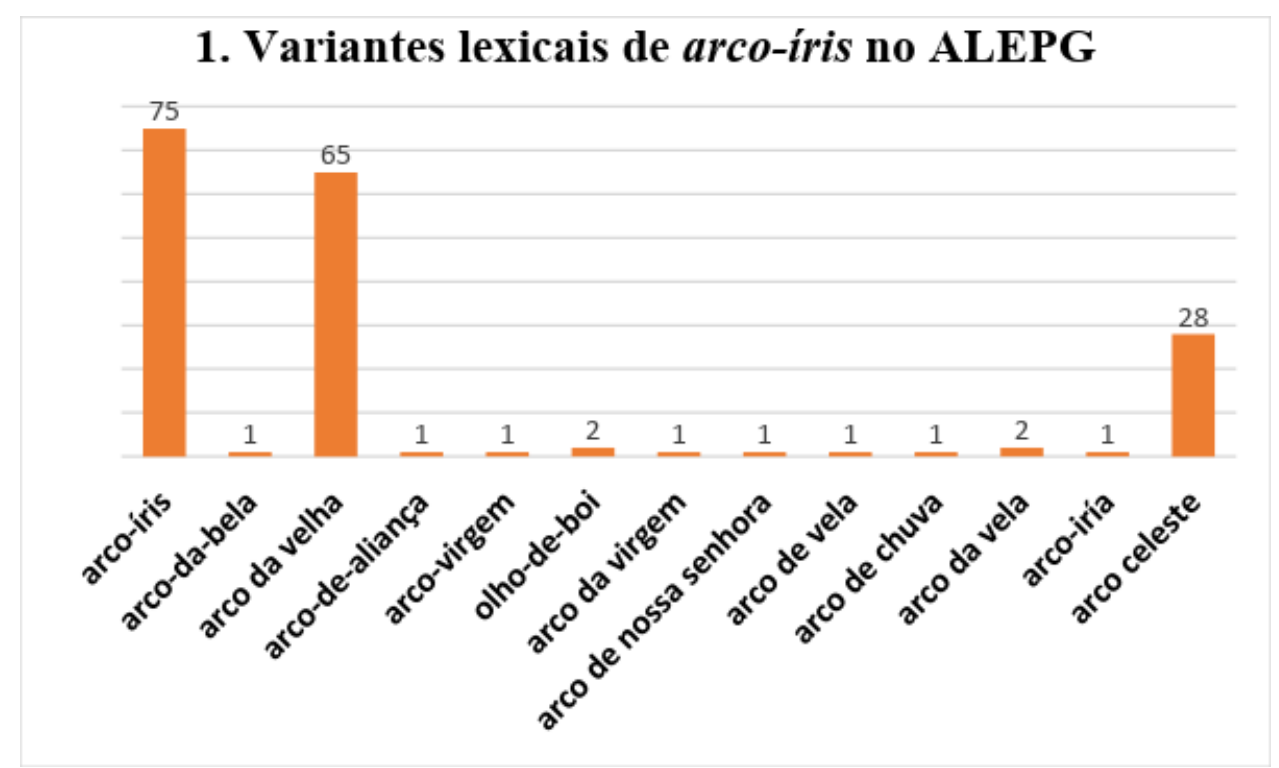

Fonte: Produzido pelo autor, com base nos dados do ALEPG.

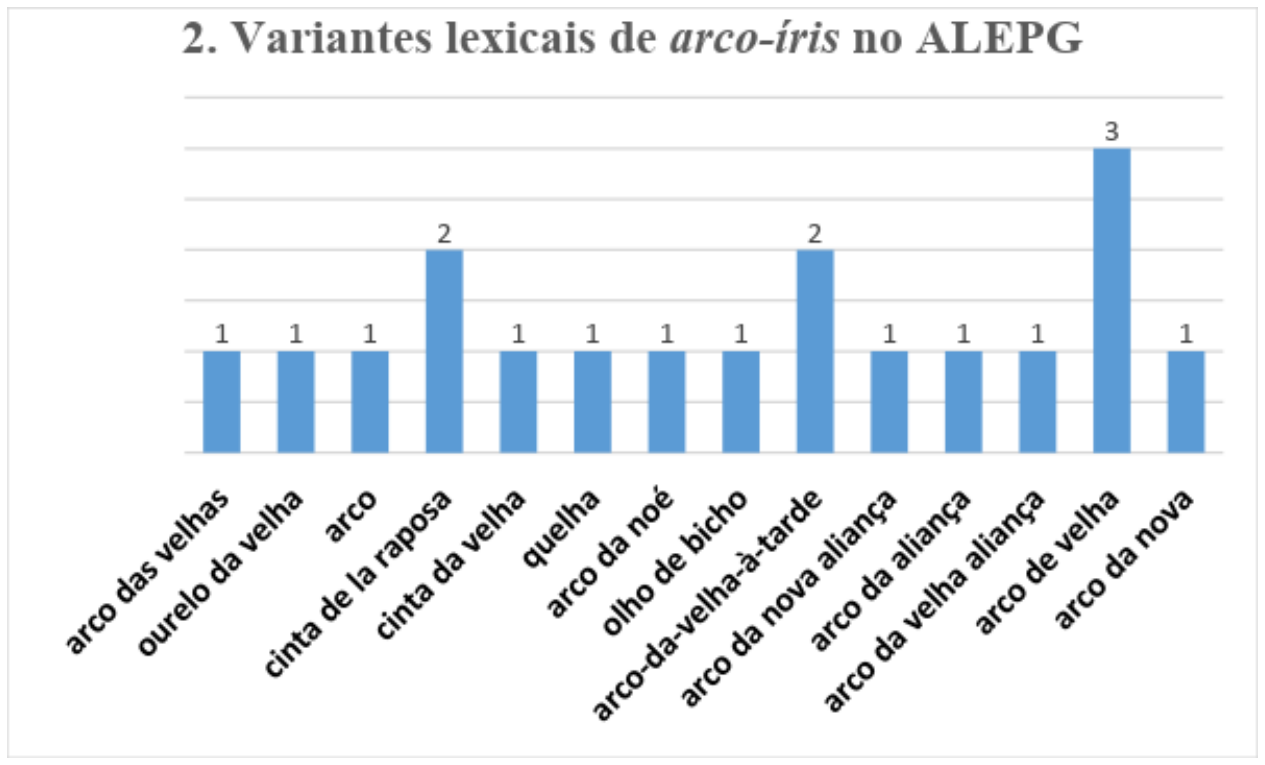

Fonte: Produzido pelo autor, com base nos dados do ALEPG. 
Figura 1. Variantes lexicais do conceito arco-íris em Portugal

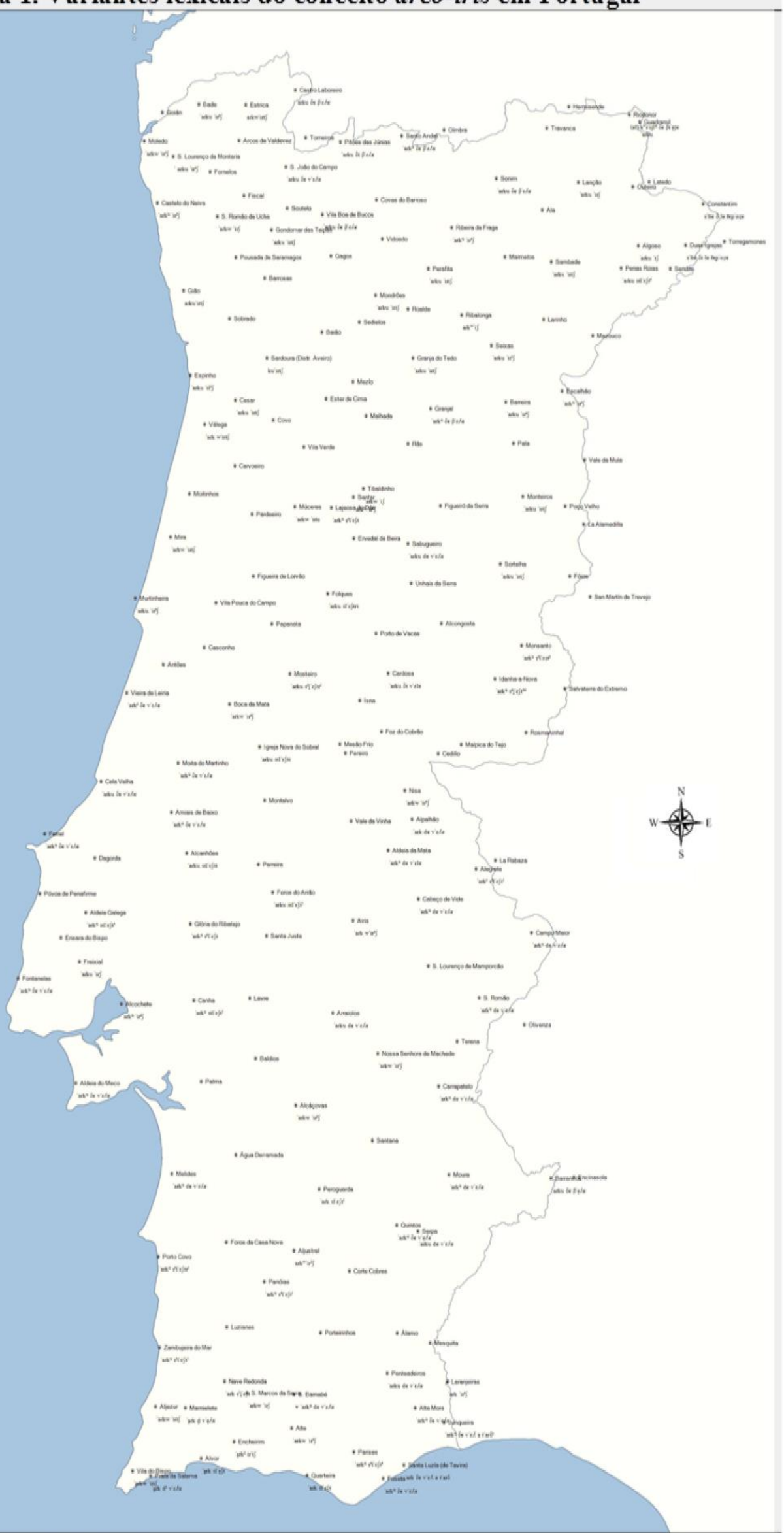

Fonte: Base de dados do ALEPG. 
Com base nos dados dos atlas, a variante léxica "arco-celeste" (maior em ocorrência no Alpa, $3^{\text {a }}$ maior em ocorrência no ALEPG, com apenas dois registros no ALERS) demonstra uma maior semelhança diatópica de áreas linguísticas do léxico entre o português da Paraíba e o português europeu, ao invés deste com o léxico da Região Sul do Brasil, no tocante ao conceito analisado.

A variante "as barras" só aparece documentada no Alpa, o que evidencia o caráter diatópico desta lexia como pertencente ao português paraibano, sem registros na língua falada na Região Sul do Brasil. Entretanto, não é possível afirmar categoricamente que a referida variante seja exclusiva da Paraíba, pois seria necessário avaliar a documentação de outros atlas linguísticos regionais brasileiros para se tirar conclusões mais precisas acerca da existência deste item lexical em outras regiões do país; ou, como é salutar na construção científica, para se levantar dúvidas que demandem a recolha de novos dados mediante novas investigações de campo, a fim de se construírem novos saberes.

\subsection{Variantes lexicais para o conceito de córrego}

Os conceitos para os Atlas Linguísticos são estabelecidos a partir de um lema, que consiste numa forma lexical padrão, que permite agrupar variantes (Cf. ALVAREZ et al.). Nesta perspectiva, a lematização de um conceito trata-se do estabelecimento da variável léxico-semântica ou semântico-lexical, com vistas a uma delimitação do referente contextual ou extralinguístico, para o qual serão empregados lexemas ou itens lexicais, que são denominadas de variantes lexicais.

Nos três Atlas Linguísticos investigados, esse processo de lematização é realizado com denominações diferentes para um mesmo conceito, o que já evidencia um processo de variação linguística, ao se buscar um lexema para constituir-se como a variável que irá agrupar as variantes lexicais, ou seja, todas as possibilidades de realização léxica para determinado conceito. Assim, no ALEPG, encontra-se o conceito de regato, que corresponde ao mesmo conceito de córrego no Alpa e ao conceito de riacho no ALERS. Além disso, o ALERS possui o conceito de arroio, que é um desdobramento semântico de riacho.

No tocante ao conceito de riacho, com base nos dados do ALERS, a variante lexical "arroio", que morfologicamente também foi registrada no diminutivo, nas 
formas "arroinho" e "arroiozinho", aparece mais frequentemente no Estado do Rio Grande do Sul, conforme gráfico abaixo:

\section{Riacho - variantes lexicais}

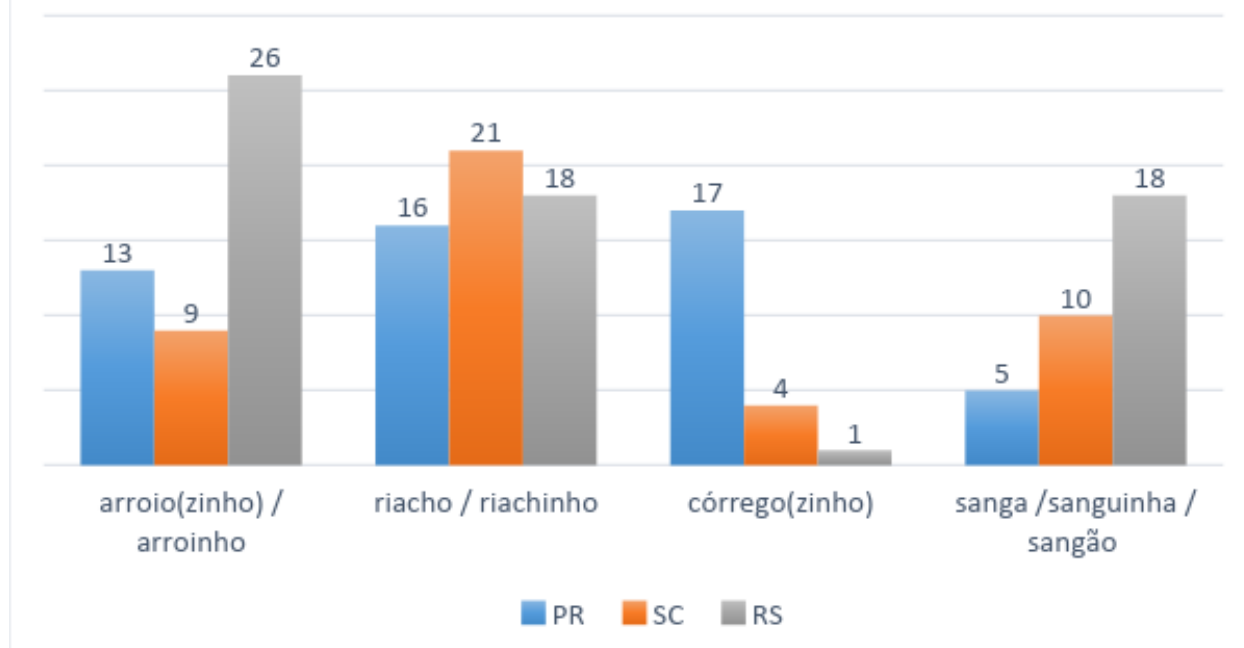

Fonte: Produzido pelo autor, com base nos mapas e quadros do ALERS.

No Paraná, as variantes mais frequentes, respectivamente, são "córrego" e "riacho". Na Paraíba, com base nos dados do Alpa, não se constata o registro da variante "arroio" em nenhum dos pontos de inquérito, o que comprova a espacialização do item lexical, constituindo-se como uma variante diatópica dos Estados da Região Sul do Brasil e mais caracteristicamente do Rio Grande do Sul, em virtude da elevada frequência de sua documentação neste Estado.

Para designação do conceito de córrego, a variante lexical que teve um maior número de ocorrências nos pontos de inquérito do Alpa, foi "riacho", conforme o gráfico abaixo: 


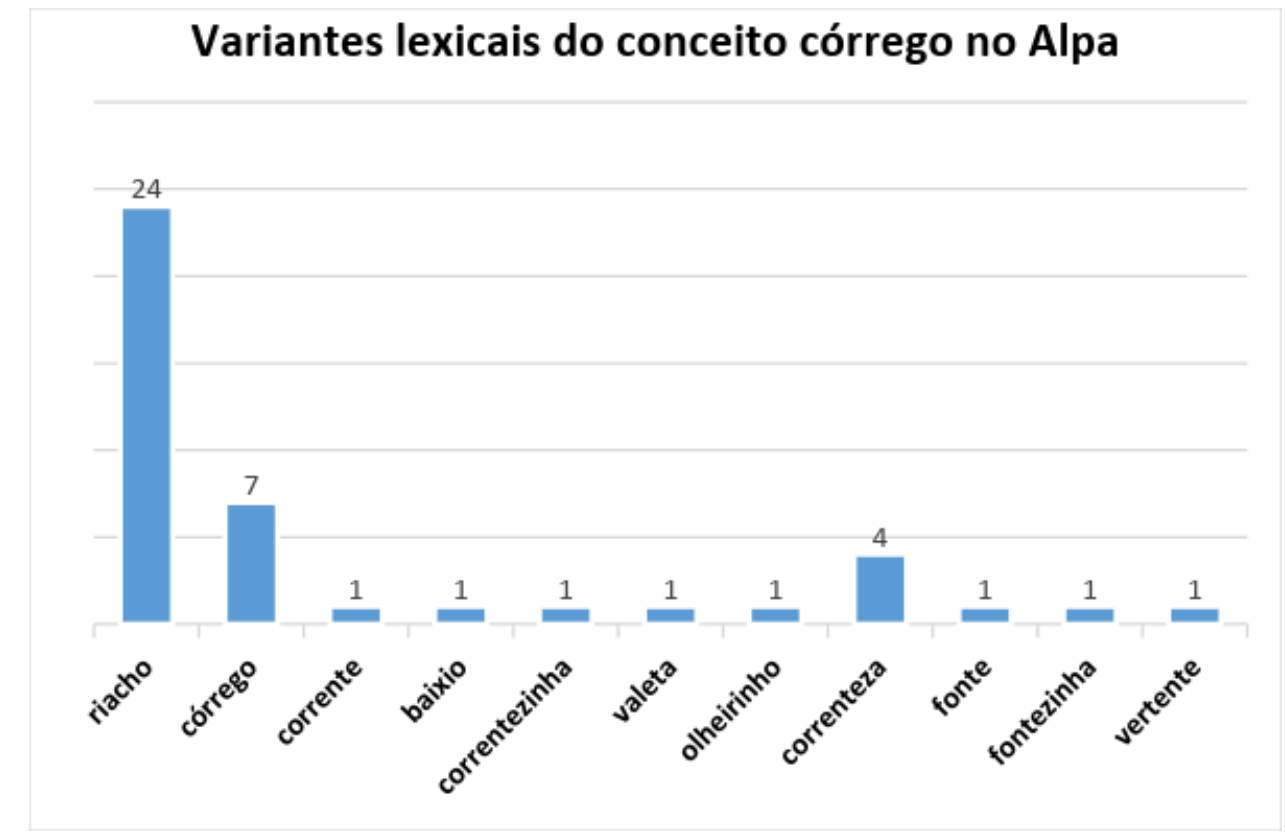

Fonte: Produzido pelo autor, com base nos mapas e quadros do Alpa.

A ocorrência da variante "riacho", cuja documentação consta de 55,8\% do total das realizações que se encontram representadas no mapa, demonstra o uso frequente desse lexema quanto à designação do conceito supracitado no cotidiano da língua falada do Estado da Paraíba. O item lexical "córrego", estabelecido para a lematização do conceito, aparece em segundo lugar, no número de ocorrências, em apenas 7 pontos de inquérito. No entanto, sua distribuição regional aparece em todas as regiões do estado, exceto no Piemonte da Borborema (nome da microrregião na década de 1980, época em que o atlas foi produzido). Atualmente é denominada como microrregião de Guarabira.

\section{Considerações Finais}

Fica explícito pelos dados do ALERS que a denominação popular, expressa nas variantes lexicais, parece contrariar a designação postulada pelos pesquisadores desse atlas no processo de lematização do conceito, posto que no conceito analisado a variante com maior frequência de registro não é a forma lematizada.

Nos dados do Alpa, em conceitos como arco-íris e córrego, os itens lexicais que denominam o conceito não foram documentados nas respostas dos informantes como as variantes lexicais de maiores ocorrências, o que revela como a dinâmica da língua 
falada muitas vezes transgride os processos de estabelecimento de uma norma a partir da escrita.

Destacamos que as análises realizadas, neste artigo, possuem um caráter parcial, posto que englobam apenas dois conceitos referentes às variedades lexicais nos atlas investigados. Entretanto, os dados linguísticos descritos poderão tornar-se elementos para palestras e discussões pedagógicas destinadas a professores e alunos das escolas públicas, no concernente à temática da variação lexical em territórios diferentes onde é falada a língua portuguesa.

Caminhemos, pois, enquanto romeiros da esperança por um ensino público gratuito de maior qualidade, com a socialização dos saberes dialetais, que nos constituem como sujeitos históricos, cidadãos e com direito a um uso cada vez mais competente de nossa língua materna, nas suas múltiplas faces léxicas, fonéticas, morfossintáticas e semânticas.

\section{Referências}

AGUILERA, Vanderci de Andrade (Org.). A geolinguística no Brasil: caminhos e perspectivas. Londrina: Eduel, 1998.

ALTENHOFEN, Vilson Cléo; KLASSMANN, Mário Silfredo (Org.). Atlas Linguístico-Etnográfico da Região Sul do Brasil - Cartas Semântico-lexicais. Porto Alegre: Editora da UFRGS; Florianópolis: Editora da UFSC, 2011.

ÁLVAREZ PÉREZ, Xosé Afonso; SARAMAgO, João António das Pedras. "Áreas lexicais galegas e portuguesas: um novo olhar para a proposta de Cintra". Estudis Romànics, XXXIV, 2012, p. 55-97.

ÁLVAREZ, Rosário et al. Presentación de un corpus digital de léxico tradicional: el tesouro do léxico patrimonial galego e portugués. Disponível em: https://s3.amazonaws.com/academia.edu.documents/30874856/FD_texto.pdf.

ARAGÃO, Maria do Socorro Silva de.; BEZERRA DE MENEZES, Cleusa P. Atlas Linguístico da Paraíba. Brasília: UFPB/CNPq, Coordenação Editorial, 1984; v. 1, 2.

BARROS FERREIRA, Manuela Barros et al. "Variação linguística: perspectiva dialectológica". In: FARIA, Isabel Hub et al. Introdução à Linguística Geral e Portuguesa. Lisboa: Caminho, 1996. 
BORTONI-RICARDO, Stella Maris. Manual de Sociolinguística. São Paulo: Contexto, 2014.

BRANDÃO, Silvia Figueiredo. A geografia linguística no Brasil. São Paulo: Ática, 1991.

CALVET, Louis-Jean. Sociolinguística: uma introdução crítica. Tradução: Marcos Marcionilo. São Paulo: Parábola Editorial, 2002.

CARDOSO, Suzana Alice Marcelino. Geolinguística: tradição e modernidade. São Paulo: Parábola Editorial, 2010.

LABOV, Willian. Padrões sociolinguísticos. Tradução: Marcos Bagno et al. São Paulo: Parábola, 2008.

TARALLO, Fernando. A pesquisa sociolinguística. São Paulo: Ática, 2002.

VILLALVA, ALINA; SILVESTRE, João Paulo. Introdução ao estudo do léxico: descrição e análise do Português. São Paulo: Vozes, 2014. 